Thorax (1966), 21, 359.

\title{
Intermittent positive pressure ventilation in the treatment of severe crushing injuries of the chest
}

\author{
M. AMB I A VAGAR, J.S. ROBINSON, I. M. MOR R ISON, A D \\ E. SHER WOOD JONES
}

From the Intensive Care Unit and Clinical Pharmacology Unit (University of Liverpool), Whiston Hospital, Prescot, Lancashire

Chest injuries causing respiratory failure have been treated in an intensive care unit during the last three years. Tracheostomy and mechanical ventilation combined with adequate metabolic care have proved effective therapy, and mechanical fixation has not been necessary.

Patients were admitted from the casualty department or were referred by the consultants in charge of them from other wards and hospitals. The physician and anaesthetist in charge of the intensive care unit then had complete responsibility for them and worked in consultation with other specialists as the need arose.

Intermittent positive pressure ventilation (I.P.P.V.) via a tracheostomy is now widely accepted as the treatment of choice for the severely crushed chest; the details of its application are described and the main problems encountered are discussed.

\section{PLAN OF TREATMENT}

The method of treatment is based on that described by Avery, Mörch, Head, and Benson (1955) and Avery, Mörch, and Benson (1956), who used I.P.P.V. to eliminate spontaneous respiratory effort and internally to splint fractures of the bony thoracic cage. Our management consisted of investigation, bronchoscopy, tracheostomy, mechanical ventilation, and biochemical monitoring. When flail segments were present, causing paradoxical respiration, triggering of the respirator or 'fighting the machine' was prevented in order to immobilize the fracture sites and so enable the bones to heal in the optimal position. When admission had been delayed, respiratory distress needing urgent relief was treated by intubation and manually assisted ventilation while assessment was carried out.

INDICATIONS FOR MECHANICAL VENTILATION Patients admitted to hospital were divided into two clinical groups. The first consisted of patients who did not have respiratory insufficiency severe enough to require mechanical ventilation. The efficiency of coughing was not seriously impaired, pain was easily controlled with analgesic drugs, and there were no significant alterations in blood gas tensions. Careful maintenance of nutrition and judicious use of analgesic drugs, physiotherapy, and antibiotics prevented complications such as retention of secretions, lung collapse, and bronchopneumonia that might have led to respiratory failure. These patients will not be discussed further in this report.

The second group consisted of 14 patients who showed signs of respiratory insufficiency with severe respiratory distress, inability to cough effectively, or arterial hypoxaemia and hypercapnia. All these features were present in different grades of severity in all patients in this group. The need for mechanical ventilation was immediately apparent in 11 patients with extensive chest wall and lung injuries. In three patients I.P.P.V. was used when treatment with analgesic drugs, physiotherapy, oxygen therapy, drainage of air and blood from the pleural cavities, and metabolic care had proved inadequate. These patients showed increasing and continuing dyspnoea, pain, and cyanosis and were unable to cough effectively. Their arterial oxygen and carbon dioxide tensions became abnormal. The injuries these three patients suffered were relatively minor but resulted in respiratory failure because the patients were already handicapped by pre-existing lung disease, 
and the measures were not enforced vigorously enough at the outset. Two of these patients are described (cases 2 and 6).

ChOICE OF Ventilator The East-Radcliffe, Cape, and Bird (Mk. 8) ventilators have been used with success (Table I). The particular ventilator chosen depended to a large extent on the familiarity of the operator with the apparatus. It was essential

T A B L E I

EFFICIENCY OF VENTILATORS USED

\begin{tabular}{|c|c|c|c|c|}
\hline Ventilator & $\begin{array}{l}\text { No. of } \\
\text { Patients }\end{array}$ & $\begin{array}{c}\text { Airway } \\
\text { Pressures } \\
\left(\mathrm{cm} . \mathrm{H}_{2} \mathrm{O}\right)\end{array}$ & $\begin{array}{c}\text { Arterial } \mathrm{PCO}_{2} \\
<30 \mathrm{~mm} \text {. Hg } \\
\text { (no. of } \\
\text { patients) }\end{array}$ & $\begin{array}{c}\text { Arterial } \mathrm{Po}_{2} \\
>80 \mathrm{~mm} . \mathrm{Hg} \\
\text { (no. of } \\
\text { patients) }\end{array}$ \\
\hline $\begin{array}{l}\text { East Radcliffe } \\
\text { Cape } \\
\text { Bird Mk. } 8\end{array}$ & $\begin{array}{l}9 \\
3 \\
2\end{array}$ & $\begin{array}{l}15-30 \\
20-30 \\
15-20\end{array}$ & $\begin{array}{l}8 \\
3 \\
2\end{array}$ & $\begin{array}{l}7 \\
2 \\
2\end{array}$ \\
\hline
\end{tabular}

to be able to ventilate the lungs with oxygenenriched mixtures from a machine which could deliver $100 \%$ oxygen. The ventilator need not incorporate a triggering device and the ability to produce a negative phase was not required. It should be able to ventilate the lungs comfortably with minute volumes of 25 litres/minute. The more versatile machine was to be preferred, but the East-Radcliffe was adequate for most purposes. This machine was most commonly used because the nursing staff understood it best. It was quiet and reliable and did not cause more pain during inflation than any of the other machines. The efficiency of each ventilator in lowering $\mathrm{PaCO}_{2}$ or raising $\mathrm{PaO}_{2}$ is shown in columns 4 and 5 of Table I. Wave-form and cycling characteristics were found to be of minor importance.

INITIAL ASSESSMENT Patients with chest injuries often have other damage which needs surgical treatment. This is best assessed and treated by traumatic surgeons who see the patients with the intensive care team on admission. The patients' clinical condition determined priorities in resuscitative measures. When respiratory distress was severe, the patient was intubated, and ventilation was manually assisted while loss of blood and extent of trauma were assessed. Muscle-relaxant drugs were never used until the patient had been thoroughly examined.

Accidents that cause crushed chest also cause diaphragmatic rupture (Bryan, 1921) and tears of the trachea and bronchi (Mahaffey, Creech, Boren, and DeBakey, 1956). These injuries require urgent surgical treatment and can be diagnosed by radiography and bronchoscopy. For this reason, antero-posterior and lateral chest radiographs were taken before commencing I.P.P.V. Bronchoscopy was then carried out under general anaesthesia, $\overrightarrow{\vec{\omega}}$ unless the patient was unconscious, in order to 0 detect tracheobronchial tears and to clear the air- $\bar{O}$ ways of foreign material. This was regarded as an $\overline{\frac{\rho}{7}}$ essential procedure and was only deferred when $\stackrel{\mathbb{Q}}{\varrho}$ respiratory distress was severe, when significant blood loss had occurred, and the stomach was full and could not be satisfactorily decompressed without adding to the patient's distress. In these instances, transfusion and manual ventilation were commenced, and the patient's airways were cleared $\overrightarrow{\vec{x}}$ as necessary by suction via the endotracheal tube. Deterioration of the clinical condition at this stage might indicate developing pneumomediastinum due to tracheobronchial tears.

THE TRACHEOSTOMY AND ITS CARE All patients were initially intubated with an endotracheal tube, $\subseteq$ and tracheostomy was deferred until it could be carried out under general anaesthesia with con- $\vec{\bullet}$ trolled ventilation. For reasons of convenience, $\stackrel{\circ}{\circ}$ plastic surgeons did all the tracheostomies, and vertical skin incisions were preferred because the upper edges of horizontal wounds were found to become oedematous, making it difficult to change the tracheostomy tubes.

The methods used in the care of the tracheostomy were reviewed by Hunter (1963). We used cuffed Radcliffe tubes, and the cuffs were released twice daily for a minute at a time. It was necessary to use the stiff, angulated Pinkerton (1955) catheters (17 F.G.) to enter and clear the left main bronchus. The risk of respiratory infection was reduced by strict barrier nursing, by wearing disposable polyethylene gloves during aspiration of the tracheostomy (as recommended by Professor A. Crampton Smith), by using individually packed sterile catheters and a no-touch technique (Robinson, 1963b), and by spraying the tracheostome with Polybactrin and nystatin.

The removal of secretions was attempted by trying to reduce their viscosity, by hydrating the o patient adequately, and by dilution of the secretions with sterile saline and humidification 0 from the ventilator. Each hour $5 \mathrm{ml}$. of sterile $\omega$ saline $(150 \mathrm{mEq} /$ litre) was injected down the trachea, and the humidifier was maintained at $100^{\circ} \mathrm{F}$.

MONITORING DURING Ventilation Pulmonary ventilation was assessed by clinical examination, measurement of ventilatory volumes, and by $\mathbb{D}$ estimation of blood gas tensions: the relative value of these is considered later. Expired minute and tidal volumes were measured with a Wright's 
anemometer and charted hourly together with the pressures indicated on the manometer of the ventilator. Hourly blood pressure, pulse rate, and fluid intake and output charts were also considered essential. Tracheostomy care and the keeping of charts were the responsibility of the nursing staff.

Arterial $\mathrm{CO}_{2}$ tension $\left(\mathrm{PaCO}_{2}\right)$ was measured with the Severinghaus electrode (Severinghaus and Bradley, 1958), $p \mathrm{H}$ with the EIL replaceable capillary electrode model SHH 33, and oxygen tensions with the EIL Bishop oxygen electrode system model SOH 33 (Bishop and Pincock, 1959); the readout instrument was the Vibron electrometer model $33 \mathrm{~B}$. These measurements were performed by a research biochemist and the resident medical staff working on the intensive care unit, who had special training in their use.

Antero-posterior chest radiographs were taken daily for the first three days, and then on the fifth, seventh, and ninth days of the illness and on the day of discharge. In two instances, posterior oblique views were necessary to diagnose collapse of the right lower lobe into the paravertebral gutter obscured by hyperinflation of the middle and upper lobes. All films were taken with a mobile, motorized $x$-ray unit powered from special $30 \mathrm{amp}$. outlets while the patient held his breath, or mechanical ventilation was temporarily discontinued.

Narcotic drugs were withheld because the patients were being passively hyperventilated, and it has been shown that passive hyperventilation in healthy volunteers produced analgesia and euphoria (Robinson, 1963a). All except one of the patients remained comfortable and free of pain during treatment. This one patient (case 3 ) was very extensively injured and required pethidine.

TERMINATION OF MECHANICAL VENTILATION Mechanical ventilation was terminated when the patient was able to breathe deeply and cough effectively without distress, when there was no arterial hypoxaemia during mechanical ventilation with air, paradox had disappeared, and the chest radiograph was normal. Ventilation was discontinued and the chest wall inspected for paradoxical movement of flail segments with the patient breathing spontaneously. If paradox was minimal or absent, ventilation was assisted with a patienttriggered (Bird, Mk 8) ventilator. During the next two days trigger-sensitivity was reduced and the patient was allowed increasing periods off the ventilator. Mechanical ventilation was then stopped and the cuffed tracheostomy tube was replaced with a silver speaking tube. If the clinical condition did not deteriorate over the next 24 hours, the tracheostome was covered with a sterile pad and allowed to close spontaneously.

metabolic care during Ventilation Metabolism was maintained by intragastric tube feeding or intravenous therapy (Jones and Sechiari, 1963 ; Jones and Peaston, 1966). Thirteen patients received a standard intragastric regime of $3,000 \mathrm{ml}$. of a complan-glucose mixture in every 24 hours (125 ml. per hour) via a Ryle's tube. The mixture was composed of $100 \mathrm{~g}$. complan, $100 \mathrm{~g}$. glucose, and $3 \mathrm{~g}$. methylcellulose (Celevec) per litre of solution. This provided $2,565 \mathrm{ml}$. water, 2,550 cals., $93 \mathrm{~g}$. protein, and $48 \mathrm{~g}$. fat per day. Intake of sodium was $66 \mathrm{mEq}$ per day and of potassium $84 \mathrm{mEq}$ per day. One patient, J. H. (case 3), developed paralytic ileus and required intravenous feeding. A basic regime of Aminosol-fructoseethanol 1.5 1., Intralipid 1 1., Aminosol $10 \%$ $500 \mathrm{ml}$., with added potassium supplements, 75 $\mathrm{mEq}$ per day, was used, the quantities given in each 24-hour period being controlled by external balance studies.

\section{RESULTS}

Fourteen cases of respiratory failure from chest trauma were treated by intermittent positive pressure ventilation. Five patients died-one of an avoidable cross-infection and four of irrecoverable damage, in two to the lungs, in one each to the head and to the spinal cord. The only complications during treatment were collapse of the lung and pulmonary infection (Table II). Seven patients

T A B L E I I

PULMONARY COMPLICATIONS

\begin{tabular}{c|c|c|c}
\hline $\begin{array}{c}\text { No. of Patients } \\
\text { Treated }\end{array}$ & $\begin{array}{c}\text { Clinically } \\
\text { Significant } \\
\text { Infection (no. } \\
\text { of patients) }\end{array}$ & $\begin{array}{c}\text { Pulmonary Col- } \\
\text { lapse requiring } \\
\text { Bronchoscopy } \\
\text { and Reinflation }\end{array}$ & $\begin{array}{c}\text { Death from } \\
\text { Complications }\end{array}$ \\
\hline 14 & 7 & 8 & 1 \\
\hline
\end{tabular}

had chest infections, six of them minor ones, but one died (see fifth case history). None of the survivors had residual chest deformities. In six patients with severe lung contusions there was marked arterial hypoxaemia despite adequate pulmonary hyperventilation with $100 \%$ oxygen (Table III (see also section on Pathology in the Discussion)).

CLINICAL FEATURES AND MANAGEMENT The variety of problems encountered during the course of 
T A B L E II I

EFFECTS OF EXTENSIVE LUNG CONTUSIONS ON GASEOUS HOMOEOSTASIS

\begin{tabular}{|c|c|c|c|c|c|c|}
\hline Patient & Ventilator & $\begin{array}{l}\text { Airway } \\
\text { Pres- } \\
\text { sure } \\
(\mathrm{cm} \text {. } \\
\left.\mathrm{H}_{2} \mathrm{O}\right)\end{array}$ & $\begin{array}{c}\text { Minute } \\
\text { Volume } \\
\text { (I.) }\end{array}$ & $\begin{array}{l}\text { Arterial } \\
\mathrm{PCO}_{2} \\
(\mathrm{~mm} \text {. } \\
\mathrm{Hg})\end{array}$ & $\begin{array}{l}\text { Arterial } \\
\mathrm{Po}_{2} \\
(\mathrm{~mm} . \\
\mathrm{Hg})\end{array}$ & $\begin{array}{l}\mathrm{A}-\mathrm{a} \\
\mathrm{DO}_{2}\end{array}$ \\
\hline $\begin{array}{l}\text { J.H. }{ }^{1} \\
\text { C.C.C. } \\
\text { G.S. }{ }^{2} \\
\text { T.T. }{ }^{2} \\
\text { T.G. }{ }^{1} \\
\text { T.H. }{ }^{2}\end{array}$ & $\begin{array}{l}\text { East-Radcliffe } \\
\text { East-Radcliffe } \\
\text { Cape } \\
\text { East-Radcliffe } \\
\text { Bird Mk. } 8 \\
\text { Cape }\end{array}$ & $\begin{array}{l}25 \\
18 \\
24 \\
25 \\
20 \\
30\end{array}$ & $\begin{array}{l}20 \\
24 \\
26 \\
15 \\
17 \\
18\end{array}$ & $\begin{array}{l}26 \\
20 \\
20 \\
55 \\
29 \\
30\end{array}$ & $\begin{array}{r}187 \\
90 \\
100 \\
87 \\
123 \\
65\end{array}$ & $\begin{array}{l}497 \\
600 \\
590 \\
568 \\
560 \\
605\end{array}$ \\
\hline
\end{tabular}

Inspired oxygen concentration in all cases was $100 \%$. Ideal alveolar oxygen tensions were calculated on the assumption that $\mathrm{PACO}_{2}=\mathrm{PaCO}_{2}$. $\mathrm{PaCO}_{2}$ was below normal in all except one patient, but, despite ventilation with pure oxygen, $\mathrm{PaO}_{2}$ remained low and the alveolararterial oxygen tension gradient was large.

${ }^{1}$ recovered; ${ }^{2}$ died.

management of all the patients is best illustrated and discussed in the following description of six cases.

Case 1 A. H. was one of seven who did not develop complications attributable to the method of treatment used.

A woman of 60 was involved in a road traffic accident when driving her car. On admission to hospital she had pain, dyspnoea, and a flail segment of the left upper chest posteriorly. During the next four hours her breathing became steadily more distressed, she was unable to cough effectively and developed cyanosis. The injuries were fractures of the second to sixth left ribs posteriorly, right clavicle, left patella, and vertebral body of D7. The chest film showed diffuse shadowing in the left lung reported as 'deaeration, probably associated with some consolidation'. When established on an East-Radcliffe ventilator, pressures of $+22 / 0 \mathrm{~cm}$. $\mathrm{H}_{2} \mathrm{O}$ produced a minute volume of $12.0 \mathrm{l}$./minute which gradually increased to $16.0 \mathrm{l} . /$ minute. There was no tendency to fight the ventilator after the initial dose of gallamine used with $\mathrm{N}_{2} \mathrm{O}: \mathrm{O}_{2}$ anaesthesia for tracheostomy. Four hours later she was conscious and free from pain. The patient was ventilated for six days, after which the chest wall became sufficiently stable to enable her to breathe spontaneously. During this period there was a low-grade fever $\left(99^{\circ}\right.$ to $101^{\circ}$ F.) but no overt evidence of chest infection, and no pathogens were cultured in the sputum. The shadowing seen in the initial chest radiograph resolved almost completely in five days. There were no residual deformities of the thorax or respiratory disabilities.

Case 2 This is one of three patients who suffered relatively minor injuries but had pre-existing chronic bronchitis and were inadequately treated in orthopaedic wards.

A 41-year-old man with chronic bronchitis fell from a ladder and sustained the following injuries: a head injury, and fractures of the left pubic ramus, left acetabulum, left wrist, and left tenth to twelfth ribs.
The patient was admitted to an orthopaedic ward and $\stackrel{\overrightarrow{\vec{s}}}{\rightarrow}$ seven days later was transferred to our intensive careo unit because he was unable to cough effectively, had흐 developed extensive pulmonary collapse, and showed $\overline{\bar{\omega}}$. signs of salt and water depletion. Bronchoscopy was $\widehat{D}$ carried out under general anaesthesia. This was followed by tracheostomy, curarization, and ventilation from an East-Radcliffe respirator. After two $\vec{\circ}$ doses of tubocurarine, moderate hyperventilation was easily maintained for eight days, after which the $\vec{\omega}$ patient recovered adequate spontaneous ventilatory $\mathscr{\omega}$ ability. During the period of mechanical ventilation $\vec{x}$ large quantities of thick purulent sputum were aspirated. Subsequent progress was satisfactory.

Case 3 This patient recovered despite very extensive trauma and multiple complications resulting from the injury.

A man of 62 fell under a railway locomotive and $\vec{c}$ sustained the following injuries: fractures of the ribs and sternum, contusions of the lungs, fractures of the pelvis, head injuries, laceration of the perineum, and $\vec{\oplus}$ other less important injuries. The patient had recently returned to work following a myocardial infarction. On admission there was shock, arterial hypotension $(70 / 50 \mathrm{~mm}$. $\mathrm{Hg})$, marked paradoxical respiration, cyanosis, and severe dyspnoea.

After examination the patient had a bronchoscopy, was intubated, curarized, and ventilated with oxygen $\mathbb{Q}$ from an East-Radcliffe ventilator (see J. H., Table III), and a blood transfusion was given. Improvement followed these measures and the blood pressure returned to normal.

During the period of hypotension a negative phase was used on the ventilator. This caused indrawing of the flail segment, but this effect disappeared when the ventilator was used without a negative phase. Exten- $\underset{x}{x}$ sive surgical emphysema and subcutaneous haema- $\dot{0}$ tomata developed. There was oliguria and paralytic ileus.

The next evening the perineal wound was excised and because of gas gangrene of the pelvic tissues a $O$ colostomy was made. There was slow improvement over the next four days, but relief of pain by hyper- $\frac{D}{O}$ ventilation was incomplete and pethidine was given when necessary. On day 6 compliance decreased, as N evidenced by increasing airway pressure and decreasing tidal and minute volumes, ventilation became inadequate, and the chest radiograph showed pulmonary oedema. Cyanosis developed despite added oxygen. There were signs of congestive cardiac failure and an electrocardiogram suggested further myocardial ischaemia. The arterial $\mathrm{PCO}_{2}$ was $44 \mathrm{~mm}$. $\mathrm{Hg}$ and the arterial $\mathrm{Po}_{2} 46 \mathrm{~mm}$. $\mathrm{Hg}$.

Fluid intake was restricted and a diuresis was induced with intravenous hydroblorothiazide. Twenty-four hours later ventilation improved, the arterial $\mathrm{Po}_{2}$ rose to $340 \mathrm{~mm}$. $\mathrm{Hg}$, and the $\mathrm{PCO}_{2}$ fell to $\stackrel{\mathbb{Q}}{\mathbb{Q}}$ $40 \mathrm{~mm}$. Hg. A chest radiograph taken later on day $6 \frac{-}{0}$ showed a right pneumothorax. This was drained and the ventilation improved still further, the minute $\delta$ 
volume increasing from 15 to $20 \mathrm{l}$./minute for the same settings of the ventilator. At this time there was fever and purulent tracheal aspirate from which Staphylococcus aureus was grown. This infection responded to cloxacillin.

On the twentieth day of ventilation the right lower lobe collapsed and a right pneumothorax was again found. This was drained through an intercostal catheter and the lung re-expanded. Mechanical ventilation was discontinued on the twenty-fourth day of intensive care.

Because of other injuries the patient remained in hospital for four months, but after convalescence he was able to return to his work.

Case 4 This case (G. S.) is described as an example of failure of this method of treatment because of extensive head injury.

A youth aged 18 was injured when riding as a passenger in a motor-car. On admission there was deep coma and bleeding from the left ear and nasopharynx. The injuries included fractures from the fourth to eleventh ribs on the right and of the fourth left rib, fractures of the left ulna and femur, a fracture of the mandible and of the neural arch of $\mathrm{Cl}$, and a fracture of the clavicle. There was paradoxical respiration with recession of the upper half of the sternum. The blood pressure was $170 / 70 \mathrm{~mm}$. $\mathrm{Hg}$. The chest film was reported as showing consolidation and de-aeration of the right base with slight changes in the right upper lobe'. The minute volume before treatment (breathing spontaneously) was $10 \mathrm{l}$./minute and the arterial $\mathrm{PCO}_{2} 46 \mathrm{~mm}$. $\mathrm{Hg}$.

After bronchoscopy the lungs were ventilated with a Cape (Smith-Clarke and Galpine, 1955) ventilator. An hour later there were signs of oligaemic shock with a blood pressure of $90 / 60 \mathrm{~mm}$. $\mathrm{Hg}$. This responded to the transfusion of two pints each of plasma and blood. Twelve hours later ventilation was satisfactory, the tidal volume was 1.0 litre, the minute volume $26 \mathrm{l}$./ minute, the arterial $\mathrm{PcO}_{2} 20 \mathrm{~mm}$. $\mathrm{Hg}$, the $p \mathrm{H} \mathrm{7.5}$, but the $\mathrm{Po}_{2}$ was only $100 \mathrm{~mm}$. $\mathrm{Hg}$, although the inspired oxygen concentration was $100 \%$ (Table III). During the first four days there were signs of decerebrate rigidity, and fits commenced which eventually required curarization, though with mechanical ventilation there were no pulmonary complications or side-effects. In the next four days the signs of damage to the central nervous system increased and the patient died on day 8. Complete thrombosis of the dural venous sinuses was found at necropsy.

Case 5 The fifth case history is of the only patient (E. C.) who died of cross-infection.

A boy aged 17 years was injured in a road traffic accident and admitted directly to our intensive care unit with a closed head injury. He had a subarachnoid haemorrhage and traumatic hemiparesis, compound fracture of the mid-shaft of the right tibia, fracture of the neck of the scapula, fracture of the right first metacarpal, extensive subcutaneous haematomata, and intrapleural and intrapulmonary bleeding as shown radiologically and subsequently confirmed at thoracotomy. There were no rib fractures. The report on the chest film on admission was 'right haemopneumothorax is present with intrapulmonary haemorrhage in the right lower lobe'. A second film taken four hours later was reported as showing 'shadowing probably due in part to pulmonary oedema and to de-aeration, but intrapulmonary haemorrhage cannot be excluded'.

For the first 16 hours treatment consisted of intercostal drainage of the right pleural cavity and transfusion of six pints of blood. It became evident that the bleeding was continuing, and the patient's condition deteriorated with a systolic blood pressure of $50 \mathrm{~mm}$. Hg. A thoracotomy showed laceration of the right lower lobe which was infiltrated with blood, and the right pleural cavity contained five pints of clotted blood. The right lower lobe was removed, the pleural cavity was drained, and a tracheostomy was made, after which the patient was returned to the unit and mechanical ventilation was started. During the first 24 hours the patient received 19 pints of blood and developed a bleeding diathesis. On day 3 there was fever and on day 5 Pseudomonas pyocyanea was isolated from the sputum.

From the fourth day the patient showed clinical and electrocardiographic signs of right heart failure and had a systemic blood pressure of $170 / 90 \mathrm{~mm}$. Hg. It was difficult to inflate the lungs and blood oxygenation was inadequate.

The right heart failure progressed and the patient died on day eight.

Case 6 The last case history describes an unexpected death from lung trauma.

A man of 53, who gave a long history of chronic bronchitis with winter exacerbations, sustained fractures to two upper right ribs in a motor-car accident. The chest radiograph on admission showed a high left diaphragm and changes in the lung fields due to chronic bronchitis but no contusions. The respiratory reserve was poor, and because of pain the cough was ineffective.

At an exploratory thoracotomy the diaphragm was found to be atrophic but not recently injured; it was plicated. Post-operatively pain restricted respiratory effort and the patient was unable to cough effectively. He was therefore curarized, intubated, and established on the Cape ventilator.

During treatment the right middle and lower lobes collapsed, but re-expanded following bronchoscopic aspiration of the airways. Ventilation was continued for 36 hours, and at the end of this time the patient was able to breathe adequately. The tracheobronchial tree was kept free from secretions with physiotherapy and analgesics.

During the next four days the patient showed steady improvement, but the sputum became purulent and viscid. He was given methyl cysteine inhalations from 
a triggered Bird ventilator, as this irritant substance causes bronchorrhoea and coughing and it was hoped that it would help to make the sputum less tenacious and easier to cough up.

The patient complained of insomnia and was given sedatives. On the fourth night there was coma, hypoventilation, and inability to cough. A further bronchoscopy was required to clear the airways, and the lungs were again ventilated for 24 hours with oxygen from the Bird machine. The endotracheal tube was then removed and the patient continued to improve: a respiratory tract infection was controlled. On the twelfth day the patient suddenly collapsed and died despite cardiac massage.

At necropsy blood was found in the airways and lung parenchyma, but the site of bleeding could not be found.

\section{DISCUSSION}

RATIONALE OF TREATMENT BY I.P.P.V. Intermittent positive pressure ventilation without mechanical fixation has been in use for 10 years to treat severe crushing injuries of the chest (Table IV).

T A B L E I V

VENTILATOR TREATMENT OF THE CRUSHED CHEST

\begin{tabular}{l|r|r}
\multicolumn{1}{c|}{ Authors and Date } & \multicolumn{2}{|c}{ Patients } \\
\cline { 2 - 3 } & No. Treated & No. Survived \\
\hline Avery, Mörch, and Benson & 1 & 1 \\
(1956) & 1 & 0 \\
Boyle et al. (1957) & 6 & 3 \\
Griffiths (1960) & 8 & 7 \\
Fairley and Chambers (1960) & 8 & 7 \\
Windsor and Dwyer (1961) & 1 & 1 \\
Clarkson and Robinson (1962) & 38 & 33 \\
Griffiths (1963) & 2 & 11 \\
Hunter (1964) & 17 & 6 \\
Göthman and Högman (1964) & 9 & 4 \\
Whitwam and Norman (1964) & 5 & 16 \\
Williams and Zeitlin (1965) & 27 & \\
Norlund (1966) & & \\
\hline
\end{tabular}

This form of treatment is aimed at eliminating respiratory insufficiency, which is the major cause of death in chest injuries. We think that (1) with a damaged chest wall, coughing is ineffective, (2) the mechanical efficiency of the breathing muscles, which is ordinarily low (Otis, 1954), is further reduced, thereby increasing the oxygen cost of breathing, and (3) damage to the lungs interferes with gas exchange. If it is efficiently maintained until the patient recovers natural function, mechanical hyperventilation via a tracheostomy splints broken ribs, eliminates the work of breathing, and permits removal of secretions. We and many others (Table IV) are convinced that this is the correct treatment of reversible breakdowns in the mechanisms of breathing.

In our experience, fixation and traction are un- necessary, and the only cogent objection to the therapeutic application of prolonged I.P.P.V. is its lack of ready availability. Specialized equipment and staff need to be concentrated in a specially designed unit (Special article, 1964), and all patients being treated by artificial pulmonary ventilation need devoted attention throughout their illness. Some writers advocate a combination of mechanical ventilation and fixation with or without traction, and this approach probably dates back to Watson-Jones (1943). In 1945 Hagen reported the first patient successfully treated by artificial ventilation alone, using a Drinker respirator. Cabinet-type ventilators, however, have numerous practical shortcomings.

Nosworthy (1941) first showed that I.P.P.V. via. an endotracheal tube eliminated the disturbances of respiratory physiology occurring during thoracis: surgery. Carter and Giuseffi (1951) reported on the beneficial effects of tracheostomy in chest injuries, and Lassen (1953) and Ibsen (1954) showed during the poliomyelitis epidemic of 1952 that the techniques of thoracic anaesthesia described by Nosworthy could be safely applied for prolonged periods. Despite repeated clinical demonstrations of the safety of prolonged I.P.P.V., opinion continues to be divided between those who favour fixation (Annotation, 1963) and consider I.P.P.V. dangerous (Maitland, 1963), and those who are convinced of its value in this circumstance (Bookallil, 1963 ; Griffiths, 1963). This controversy exists partly because few centres are equipped to maintain prolonged mechanical ventilation and also because the complex changes in pulmonary physiology produced by these injuries are not well understood. The extensive clinical and experimental literature on the latter was reviewed by Harley (1961) and Williams and Stembridge (1964), but knowledge is fragmentary and conclusions are speculative. The disturbance of physiology caused by 'paradoxical respiration' is not fully understood (Griffiths, 1960) and is probably not due to pendulum movement of residual air from one lung to the other during the respiratory cycle (Maloney, Schmutzer, and Raschke, 1961). Pain further limits the ability to ventilate the lungs. Intercostal nerve blocks and epidural blocks have been used to obtain relief of pain and to enable a more efficient response to physiotherapy, but their applications are limited by technical considerations.

Mechanical fixation by itself is probably an inadequate form of treatment of the complex disturbances of physiology that result from such injuries, as evidenced by the large variety of methods that are in use and continue to be devised 
(Dolley and Brewer, 1942 ; McKim, 1943 ; Jaslow, 1946 ; Blades, 1949 ; Cameron, O'Rourke, and Burt, 1949 ; Coleman and Coleman, 1950 ; Heroy and Eggleston, 1951 ; Proctor and London, 1955 ; Henry, 1957 ; Jacques and Munro, 1958 ; Sillar, 1961 ; Schrire, 1963 ; Hadfield and Watkin, 1965). Continually moving cancellous bone is difficult to fix effectively, yet only when fully effective does fixation eliminate a flail segment.

PATHOLOGY The effects of pulmonary contusion on gas exchange are not yet sufficiently understood. Table III shows that elimination of carbon dioxide was adequate but oxygenation was impossible even with $100 \%$ inspired concentration. Hypoxaemia in the presence of adequate removal of $\mathrm{CO}_{2}$ is a feature of pulmonary contusions. It is evident from our results that mechanical ventilation is adequate therapy for all patients except those with the most severe lung trauma. It is possible that treatment with hyperbaric oxygen will benefit these patients.

In our small series there has been poor correlation between the severity of the chest wall damage and the extent of the pulmonary contusion. This is in keeping with findings in larger series (Westermark, 1941; Williams and Bonte, 1962). Contusions are the primary lung pathology and are of considerable prognostic significance, being associated with increased alveolar-arterial oxygen tension gradients. A progressive decrease in the gradients accompanies improvement in the patients' clinical condition and in the appearance of the lungs in chest radiographs.

'Traumatic wet lung' and the inexplicable pulmonary oedema described by so many writers (see review by Harley (1961)) were not seen in the series. Griffiths (1960) made a smiliar observation ; two patients with crushed chests in his series, who died though treated by mechanical ventilation, showed no evidence of pulmonary oedema at necropsy. It is probable, therefore, that these conditions result largely from mechanical causes and are eliminated by efficient artificial ventilation.

TECHNIQUES Successful application of this method of treatment depends on maintenance of complete control of ventilation for the period of disability and enlightened nutritional care.

The safety of prolonged I.P.P.V. depends on close co-operation between a team of specially trained nurses and conscientious resident medical staff. A patient who is being treated by artificial pulmonary ventilation should never be left unattended, the nurses should be proficient at chang- ing tracheostomy tubes and should have a thorough grasp of the principles of artificial ventilation. A resident anaesthetist should be available within two minutes if required. All members of the team should adhere to a strict aseptic discipline, because the dangers of hospital cross-infection to the tracheostomized, severely injured patient cannot be over-emphasized. Accidents occur even with the stringent application of the principles of asepsis.

In the patient who died of a Ps. pyocyanea infection of the lungs, pulmonary ventilation was adequate and toxaemia was not overwhelming. There were clinical and E.C.G. signs of right heart failure, and it was thought that malignant pulmonary arterial hypertension had developed. This is unusual during mechanical ventilation with high concentrations of oxygen, which in other circumstances relieves pulmonary hypertension (Jones, 1966). No adequate explanation or effective therapy appears to be available for this.

Complete monitoring is the combined responsibility of the nursing and resident medical staff. Alterations in the patient's clinical condition occur very rapidly and need prompt attention. The nurses bear a heavy responsibility in the minute to minute vigil over the patient, and their task is systematized and reduced to manageable proportions by the keeping of charts. Accurate biochemical control appears essential for the maintenance of prolonged mechanical ventilation. Prediction of ventilatory requirements from nomograms (Radford, 1955) results in hypoventilation, as occurred in Hunter's (1964) cases. Clinical assessment of the adequacy of mechanical ventilation is even more fallible than the assessment of a spontaneously breathing patient ; at best only trends are apparent.

The success of this therapeutic procedure depends on maintaining complete control of ventilation. Inability to maintain such control is due either to inadequate ventilation or to psychological causes. The cause should be sought and eliminated, but muscle-relaxant drugs may be required to re-establish control and return the patient to a steady state where he is no longer at variance with his ventilator. The drug of choice in our experience is D-tubocurarine. During the period of curarization, assessment of the progress of a head injury (case 4) depends on examination of the pupils and the pulse and blood pressure charts. In our limited experience with this problem it is just possible to strike a balance between the needs of ventilation and those of the neurosurgeon. Case 4 was curarized for only 14 hours out of the 12 days he was on the ventilator. 


\section{SUMMARY}

Details of patients treated without fixation in an intensive care unit by a team of nurses, physicians, anaesthetists, and surgeons are presented with particular emphasis on the principles underlying day-to-day management.

Mechanical ventilation via a tracheostomy permits efficient removal of secretions, eliminates the work of breathing, corrects the pathological changes consequent upon abnormal mechanics of breathing, and is the most efficient means available of ensuring adequate gas exchange. Six case histories have been described in detail to illustrate problems in the treatment of major chest injuries, and some of these difficulties are discussed.

The literature on the treatment of closed chest injuries has been reviewed, and the merits and demerits of traditional fixation methods are discussed in comparison with treatment by mechanical ventilation.

The authors are indebted to Dr. D. V. Roberts for help in the preparation of this paper.

\section{REFERENCES}

Annotation (1963). The stove-in chest. Lancet, 1, 871.

Avery, E. E., Mörch, E. T., Head, J. R., and Benson, D. W. (1955). Severe crushing injuries of the chest; a new method of treatment with continuous hyperventilation by means of intermittent positive endotracheal insufflation. Quart. Bull. Northw. Univ. positive endotracheal
med. Sch., 29, 301.

med. Sch., 29, 301. . W. (1956). Critically crushed chests; a new method of treatment with continuous mechanical hyperventilation to produce alkalotic apnea and internal pneumatic stabilization. J. thorac. Surg., 32, 291.

Bishop, J. M., and Pincock, A. C. (1959). A method of measuring oxygen tension in blood and gas using a covered platinum electrode. J. Physiol., 145, 20P.

Blades, B. (1949). Physiologic principles underlying the treatment of injuries to the chest. Amer. J. Surg., 78, 665.

Bookallil, M. (1963). Stove-in chest. Lancet, 1, 1001.

Boyle, A. K., Gallie, J. R., and Murray, D. B. (1957). Crush injury of the chest. Anaesthesia, 12, 453.

Bryan, C. W. G. (1921). Injuries of the diaphragm: with special reference to abdominothoracic wounds. Brit. J. Surg., 9, 117.

Cameron, D. A., O'Rourke, P. V., and Burt, C. W. (1949). An analysis of the management and complications of multiple ( 3 or more) rib fractures. Amer. J. Surg., 78, 668.

Carter, B. N., and Giuseff, J. (1951). Tracheotomy, a useful procedure in thoracic surgery, with particular reference to its employment in crushing injuries of the thorax. J. thorac. Surg., 21, 495.

Clarkson, W. B., and Robinson, J. S. (1962). Deliberate hyperventilation in the treatment of a crush injury of the chest. Brit. $J$. Anaesth., 34, 471 .

Coleman, F. P., and Coleman, C. L. (1950). Fractures of ribs-a logical treatment. Surg. Gynec. Obstet., 90, 129.

Dolley, F. S., and Brewer, L. A. (1942). Chest injuries. Ann. Surg., 116, 668 .

Fairley, H. B., and Chambers, R. A. (1960). The management of the patient with respiratory insufficiency. Canad. Anaesth. Soc. J., 7,447

Göthman, B., and Hت̈gman, L. (1964). Current treatment of acute thoracic injuries. Acta chir. scand., 127, 609.

Griffiths, H. W. C. (1960). Crush injuries of the chest. J. roy. Coll. Surg. Edinb., 6, 13

(1963). Stove-in chest. Lancet, 1, 1108.

Hadfield, J., and Watkin, D. (1965). Device for the stabilisation of anterior chest-wall injuries. Ibid., 1, 634.
Hagen, K. (1945). Multiple rib fractures treated with a Drinker respirator: a case report. J. Bone Jt Surg., 27, 330.

Harley, H. R.S.(1961). Discussion on non-penetrating injuries of the chest and abdomen. Proc. roy. Soc. Med., 54, 558.

Henry, L. (1957). Case of stove-in chest injury. Brit. med. J., 2, 339.

Heroy, W. W., and Eggleston, F.C. (1951). A method of skeletal traction $\overrightarrow{\mathbb{D}}$ applied through the sternum in "steering wheel" injury of the $\varrho$ chest. Ann Surg., 133, 135.

Hunter, A. R. (1963). The management of patients during artificialos ventilation. In Recent Advances in Anaesthesia and Analgesic. ed. C. L. Hewer, 9th ed., pp. 308-314. Churchill, London.

(1964). Artificial ventilation of the lungs in combined head and chest injuries. Lancet, 2, 279.

Ibsen, B. (1954). The anaesthetist's viewpoint on the treatment of $\vec{\omega}$ respiratory complications in poliomyelitis during the epidemic in Copenhagen, 1952. Proc. roy. Soc. Med., 47, 72.

Jacques, J. E., and Munro, W. D. (1958). Stove-in chest ; a new method of internal fixation. $B * i t$. J. Tuberc., 52, 160.

Jaslow, I. A. (1946). Skeletal traction in the treatment of multiple $A$ fractures of the thoracic cage. Amer. J. Surg., 72, 753.

Jones, E. S. (1966). In Cardiac Resuscitation and Intensive Care. Chest and Heart Association, London (in the press).

and Peaston, M. J. T. (1966). Metabolic care during acute $ᄋ$ illness. Practitioner, 196, 271.

and Sechiari, G. (1963). Method for providing metabolic balance $\overrightarrow{-}$ during intensive patient-care. Lancet, $2,19$.

Lassen, H. C. A. (1953). A preliminary report on the 1952 epidemic of poliomyelitis in Copenhagen, with special reference to the treatment of acute respiratory insufficiency. Ibid., 1, 37.

Mahaffey, D. E., Creech, O., Jr., Boren, H. G., and DeBakey, M. E. \&ै (1956). Traumatic rupture of the left-main bronchus successfully $\sigma$ repaired eleven years after injury. J. thorac. Surg., 32, 312.

Maitland, A. I. L. (1963). Stove-in chest. Lancet, 1, 1001.

Maloney, J. V., Schmutzer, K. J., and Raschke, E. (1961). Paradoxical respiration and "Pendelluft". J. thorac cardiovasc. Surg., 41, 291.

McKim, L. H. (1943). A method of ñxation for fractures of the sternum. Ann. Surg., 118, 158.

Norlund, S. (1966). Acta chir. scand., in the press.

Nosworthy, M. D. (1941). Anaesthesia in chest surgery, with special $=$ reference to controlled respiration and cyclopropane. Proc. roy. O Soc. Med., 34, 479.

Otis, A. B. (1954). The work of breathing. Physiol. Rev., 34, 449.

Pinkerton. H. H.(1955). Endobronchial suction catheters. Aracsthesic. 10,310 .

Proctor. H.. and London, P. S. (1955). The stove-in chest with paradoxical respiration. Brit. J. Surg., 42, 622.

Radford, E. P. (1955). Ventilation standards for use in artificial respiration. J. appl. Physiol., 7, 451.

Robinson, J. S. (1963a). M.D. thesis, Liverpool University. (1963b). Therapeutic use of muscle relaxants. Bizt. J. Anclesth. 35, 570 .

Schrire, T. (1963). The organization and control of m.sttiple injuries. S. Afr. med. J., 37, 747.

Severinghaus, J. W., and Bradley, A. F. (1958). Electrodes for blood $\mathrm{pO}_{2}$ and $\mathrm{pCO}_{2}$ determination. $J$. appl. Physiol., 13, 515.

Sillar, W. (1961). The crushed chest. Management of the flail anterior segment. J. Bone Jt Surg., 43B, 738.

Smith-Clarke, G. T., and Galpine. J. F. (1955). A positive-negative pressure respirator. Lancet, 1, 1299.

Special article (1964). A unit for intensive care. Ibid., 1, 657.

Watson-Jones, R. (1943). Fractures and Joint triuries 3rd ed., Vol. 1, S p. 384. Livingstone, Edinburgh.

Westermark, N. (1941). Roentgenological investigation into traumatic lung changes arisen through blunt violence to the thorax. Acta radiol. (Stockh.), 22, 331.

Whitwam, J. G., and Norman J. (1964). Hypoxaemia after crush injury of the chest. B it. med. J., 1, 349.

Williams, J. R., and Bonte, F. J. (i962). Pulmonary hematomas

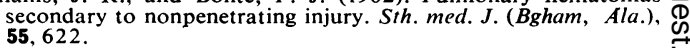

and Stembridge, V. A. (1964). Pulmonary contusion secondary to nonpenetrating chest trauma. Amer. J. Roentgenol., 91, 284.

Williams, W. G., and Zeitlin, G. L. (1965). The management of flail chest. Brit. J. Dis. Chest, $\mathbf{5 9}$, is.

Windsor, H. M., and Dwyer, B. (1961). The crushed chest. Thorax, 16, 3 . 